\title{
Editorial Comment: Cost-effectiveness of brain MRI in stroke emergency patients
}

\author{
Paulo Eduardo de Aguiar Kuriki ${ }^{1} \cdot$ Felipe Campos Kitamura $^{1}$
}

Received: 31 July 2021 / Revised: 31 July 2021 / Accepted: 21 August 2021 / Published online: 29 November 2021

(c) The Author(s), under exclusive licence to European Society of Radiology 2021

In patients with acute stroke suspected, a non-contrast computed tomography (NCCT) of the head is usually the first method used for excluding hemorrhagic stroke, helping neurologists to select those eligible for reperfusion therapy. Although this exam is useful for acute management, it has low sensitivity for detecting minor or hyperacute infarcts.

Minor strokes or transient ischemic attacks (TIAs) may precede a major stroke in $15-30 \%$ cases. Albeit the risk of a recurrent stroke or TIA is high, it can be mitigated with appropriate secondary stroke prevention. Some studies showed that targeting multiple risk factors can result in $80 \%$ cumulative risk reduction in recurrent vascular events [1].

The American Heart Association/American Stroke Association published in July 2021 the updated Guideline for the Prevention of Stroke in Patients with Stroke and Transient Ischemic Attack [2]. According to the guideline, an accurate diagnosis of ischemic stroke or TIA is essential for justifying the institution of stroke prevention therapies. It is suggested that when a computed tomography (CT) or magnetic resonance imaging (MRI) does not demonstrate acute symptomatic cerebral infarct, a follow-up CT or MRI of the brain may be reasonable to confirm the diagnosis.

In this article published in European Radiology, PuhrWesterheide et al. [3] investigated the cost-effectiveness of a supplemental short-protocol MRI performed in emergency patients after a NCCT negative for minor stroke. This study was based on a previously published prospective singlecenter diagnostic study validating the use of short-protocol MRI in an emergency setting [4]. In this study, the short

This comment refers to the article available at https://doi.org/10. 1007/s00330-021-08222-z.

Paulo Eduardo de Aguiar Kuriki

paulokuriki@gmail.com

1 DasaInova, Diagnósticos da América SA (DASA), R. Gilberto Sabino 215, São Paulo, SP 05425-020, Brazil
MRI protocol used 5 sequences, reducing the length of the protocol from 15:25 to 04:33 min.

The economic evaluation was performed using a decision-analytic Markov model distinguishing the strategies "no additional imaging" and "additional short-protocol MRI." The authors assumed minor stroke was missed in initial evaluation in $40 \%$ of patients without the short-protocol MRI. Specialized post-stroke care with immediate secondary prophylaxis was assumed for patients with detected minor strokes. Utilities and quality of life measures were estimated as quality-adjusted life years (QALYs). The Markov model simulated a follow-up period of up to 30 years. Willingnessto-pay was set to $\$ 100,000$ per QALY. Cost-effectiveness was calculated and deterministic and probabilistic sensitivity analysis was performed.

As a result, it was determined that additional shortprotocol MRI was the dominant strategy with overall costs of \$26,304 (vs CT-only: \$27,109). Cumulative calculated effectiveness in the CT-only group was 14.25 QALYs (vs short-protocol MRI group: 14.31 QALYs).

Forty percent of recurrent major strokes occur within 7 days and about $20 \%$ within $24 \mathrm{~h}$ after the initial minor stroke or TIA [5]. The EXPRESS study [6] demonstrated a rate of recurrent stroke of $2.1 \%$ in patients receiving treatment within 1 day of the index event compared to a rate $10.3 \%$ in patients receiving treatment within 3 days of the index event.

In 2012 [7], a systematic review found no evidence that multimodal MRI, when used purely for diagnostic purposes, improves outcomes. In 2014 [8], a cost-effectiveness analysis of the use of MRI in patients with TIA concluded that MRI was generally not cost-effective.

However, based on these studies confirming the importance of rapid treatment for reducing recurrent stroke rates, it is important to evaluate the cost-effectiveness of MRI performed in emergency patients to detect minor strokes.

This study has some limitations extensively discussed by the authors like the input parameters for the model that were derived from the literature. Moreover, 
the study was based on a single center. A prospective multicenter study could improve the level of evidence.

Funding No funding was received.

\section{Declarations}

Guarantor The guarantor of this work is Paulo Eduardo de Aguiar Kuriki.

Conflict of interest F.C.K. is speaker for GE Healthcare and consultant for MD.ai. P.E.A.K. declares no relationships with any companies whose products or services may be related to the subject matter of the article.

Statistics and biometry Not applicable.

Informed consent Informed consent was not required since this work is an editorial comment.

Ethical approval Ethics approval was not required since this work is an editorial comment.

\section{Methodology}

- Editorial comment

\section{References}

1. Hackam DG, Spence JD (2007) Combining multiple approaches for the secondary prevention of vascular events after stroke: a quantitative modeling study. Stroke 38:1881-1885. https://doi.org/ 10.1161/STROKEAHA.106.475525
2. (2021) Correction to: 2021 Guideline for the Prevention of Stroke in Patients With Stroke and Transient Ischemic Attack: a guideline from the American HeartAssociation/American Stroke Association. Stroke 52(7): e483-e484. https://doi.org/10.1161/STR.00000 00000000383.

3. Puhr-Westerheide D, Froelich MF, Solyanik O et al (2021) Costeffectiveness of short-protocol emergency brain MRI after negative noncontrast CT for minor stroke detection Eur Radiol. https:// doi.org/10.1007/s00330-021-08222-z

4. Kazmierczak PM, Dührsen M, Forbrig R et al (2020) Ultrafast brain magnetic resonance imaging in acute neurological emergencies. Invest Radiol 55(3):181-189. https://doi.org/10.1097/RLI. 0000000000000625

5. Amarenco P, Lavallée PC, Labreuche J (2016) One-year risk of stroke after transient ischemic attack or minor stroke. N Engl J Med 374:1533-1542. https://doi.org/10.1056/NEJMoa1412 981

6. Rothwell PM, Giles MF, Chandratheva A et al (2007) Effect of urgent treatment of transient ischaemic attack and minor stroke on early recurrent stroke (EXPRESS study): a prospective population-based sequential comparison. Lancet 370:1432-1442. https:// doi.org/10.1016/S0140-6736(07)61448-2

7. Burke JF, Gelb DJ, Quint DJ et al (2013) The impact of MRI on stroke management and outcomes: a systematic review. J Eval Clin Pract 19:987-993. https://doi.org/10.1111/jep.12011

8. Wardlaw J, Brazzelli M, Miranda H, et al (2014) An assessment of the cost-effectiveness of magnetic resonance, including diffusionweighted imaging, in patients with transient ischaemic attack and minor stroke: a systematic review, meta-analysis and economic evaluation. Health Technol Assess. 18:1-368, v. https://doi.org/ 10.3310/hta18270

Publisher's note Springer Nature remains neutral with regard to jurisdictional claims in published maps and institutional affiliations. 